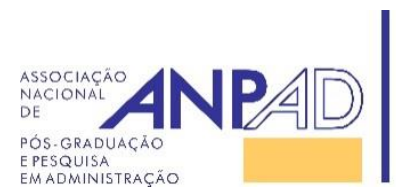

Disponível em

http://www.anpad.org.br/rac

RAC, Rio de Janeiro, v. 21, n. 3 ,

pp. 413-434, Maio/Jun. 2017

http://dx.doi.org/10.1590/1982-7849rac2017170026

$(\mathrm{cc}) \mathrm{EY}$

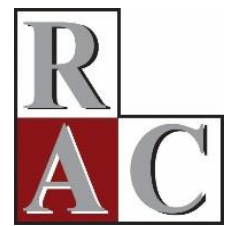

Artigos Tecnológicos:

\title{
Coprodução de Serviço de Vigilância Sanitária: Certificação e Classificação de Restaurantes
}

Co-production of Health Inspection Service: Certification and Rating of Restaurants

Luiza Moritz Age ${ }^{1,2}$

Paula Chies Schommer ${ }^{1}$

Universidade do Estado de Santa Catarina ${ }^{1}$ Secretaria Municipal de Saúde de Florianópolis ${ }^{2}$

Artigo recebido em 07.07.2016. Última versão recebida em 29.08.2016. Aprovado em 01.09.2016. Publicado online em 24.03.2017 


\title{
Resumo
}

O presente trabalho descreve o processo de elaboração de uma proposta de Certificação e Classificação por Qualidade Nutricional para restaurantes em formato bufê, a ser aplicada pelo serviço de vigilância sanitária municipal. O processo caracteriza-se pela coprodução no design de serviços públicos, visando à promoção da saúde para enfrentamento das Doenças Crônicas Não Transmissíveis (DCNT). Participaram pessoas e organizações com diferentes conhecimentos sobre o tema, reunidos em sete encontros. O roteiro de inspeção para certificação e classificação dos restaurantes foi coproduzido em seus critérios, pontuações, classificações e símbolo. A avaliação dos participantes demonstrou que a maneira pela qual se conduziu o processo foi, no geral, adequada, porém é necessário investir em outras formas de abordagem com consumidores e representações de restaurantes para que participem mais ativamente. $\mathrm{O}$ trabalho potencialmente contribui para que outros setores da vigilância sanitária municipal e demais organizações públicas desenvolvam instrumentos de trabalho de forma coproduzida, para facilitar uma escolha mais saudável de alimentos pelos consumidores, ajudar a melhorar a qualidade nutricional dos alimentos servidos em restaurantes tipo bufê, e contribuir para o enfrentamento das DCNT no âmbito municipal.

Palavras-chave: coprodução; vigilância sanitária; classificação de restaurantes.

\begin{abstract}
This research describes the development process for a proposal on Certification and Classification regarding the Nutritional Quality of buffet restaurants, to be applied by city Health Inspection Services. The process is characterized by co-production in the design of the public service, aimed at improving public health by fighting Non-Communicable Chronic Diseases (NCD). People and organizations with different knowledge on the subject participated in the process, which consisted of seven meetings. The steps for the inspection, certification and classification of restaurants were co-produced according to criteria, grades, classification and symbols. The participants considered the proposal development process to be adequate overall. However, it is necessary to invest in other approaches towards consumers and restaurant representatives in order for them to be more active participants. This research has the potential to contribute to help other sectors of city Health Inspection and other public organizations co-produce working tools; to make it easy for consumers to choose healthy food; to help improve nutritional quality of food served in buffet restaurants; and finally to contribute to fighting NCD in cities.
\end{abstract}

Key words: co-production; health inspection; restaurant rating. 


\section{Introdução}

As sociedades estão envelhecendo e seus estilos de vida estão contribuindo para um aumento da incidência e da prevalência das Doenças Crônicas Não Transmissíveis (DCNT). Estas afetam o exercício de atividades econômicas e de lazer pelos indivíduos e geram consequências negativas para a qualidade de vida das comunidades e da sociedade, de um modo geral (Malta et al., 2014). No Brasil, o percentual de adultos entre 30 e 59 anos aumentou cinco pontos entre 2004 e 2014, e a população com mais de 60 anos aumentou quatro pontos no mesmo período (Instituto Brasileiro de Geografia e Estatística [IBGE], 2015).

A obesidade é considerada um dos principais fatores de risco para as DCNT. A maior parte da população mundial vive em países em que a obesidade mata mais que a desnutrição, como os situados na América do Norte, nas Europas Ocidental e Oriental, e na Oceania. Além da inatividade física, o outro fator de risco é a ingestão de alimentos densos em calorias e ricos em gordura e açúcares (World Health Organization - Organização Mundial da Saúde [OMS], 2015). O Brasil também vem passando por uma transição epidemiológica e demográfica, com queda das mortes por doenças infectocontagiosas e aumento daquelas por DCNT, semelhante ao quadro epidemiológico mundial (Schmidt et al., 2011). É o que se observa no município de Florianópolis, no qual se desenvolveu o presente trabalho, e onde, de acordo com dados de uma pesquisa nacional realizada por telefone em 2014 (Ministério da Saúde, 2015), 55,6\% dos adultos, sendo que, desses, $45,6 \%$ das mulheres e $67,6 \%$ dos homens estão com excesso de peso, percentuais acima da média nacional (52\%, 45,4\% e 60,8\%, respectivamente).

O planejamento realizado de forma intersetorial é uma estratégia a ser considerada para ações que tem por objetivo criar ambientes que facilitam as escolhas e estilos de vida saudáveis, fortalecendo as parcerias entre governos e sociedade civil (Malta et al., 2014; Schmidt et al., 2011). Lucchese (2001) comenta que os gestores da área de vigilância sanitária pouco têm compartilhado com os cidadãos a busca pela melhor ação a ser tomada. O autor cita que essa atitude pode ocorrer pela necessidade de rapidez de grande parte das decisões e pela quantidade de incertezas que se tem ao tomar uma medida quando o assunto é saúde.

O conceito de coprodução de serviços públicos vem alcançando difusão em estudos em administração pública como um processo pertinente frente aos desafios contemporâneos e transformações na prática administrativa, particularmente no design e na entrega de serviços (Osborne \& Strokosch, 2013). As ações de promoção de saúde baseadas em processos de coprodução vêm sendo desenvolvidas em diversos países, conforme relata a organização Governance International (http://www.govint.org/, recuperado em 25 de outubro, 2016), sediada no Reino Unido.

No Brasil, as ações de promoção de saúde são também diversificadas, mas menos locais e voltadas mais para educação e não para mudanças no ambiente. Raramente envolvem o usuário no design dos serviços, pois essa é uma abordagem ainda pouco difundida no país. Exemplos de ações de promoção são a Estratégia de Saúde da Família, a Política Nacional de Alimentação e Nutrição, o Guia Alimentar para a População Brasileira e o Programa Nacional de Alimentação do Escolar (Buss \& Carvalho, 2009; Departamento de Atenção Básica, n.d.; Fundo Nacional de Desenvolvimento da Educacão [FNDE], n.d.; Ministério da Saúde, 2005).

Muitas cidades na América do Norte e no Reino Unido já aplicam, no processo de trabalho de suas vigilâncias sanitárias, a classificação de estabelecimentos de alimentação a partir das características higiênico-sanitárias do local. Avaliações demonstram resultados positivos tanto na melhora dos estabelecimentos quanto na utilização dessas classificações, pelos consumidores, para escolha do estabelecimento em que irão alimentar-se (Food Standards Agency [FSA], 2015; NYC Health, n.d.). Entretanto, não se tem conhecimento de classificações governamentais que utilizam como critério a qualidade nutricional dos alimentos servidos.

O presente trabalho se propôs a descrever a maneira pela qual a Gerência de Vigilância Sanitária do município de Florianópolis elaborou, por meio de um processo de coprodução e visando à promoção 
da saúde para enfrentamento das DCNT, a Certificação e a Classificação por Qualidade Nutricional para restaurantes em formato bufê, pela avaliação da qualidade nutricional dos alimentos servidos. São descritos os passos do processo, baseado na abordagem metodológica da design science (Aken, 2004; Jelinek, Romme, \& Boland, 2008), os resultados e as reflexões sobre a condução do trabalho, que podem servir como referência para outras áreas de vigilância sanitária e demais órgãos da administração pública, em outras localidades.

\section{Contexto e a Realidade Investigada}

Como um sistema de saúde pública, a vigilância sanitária percorreu uma trajetória histórica marcante até os dias atuais. A chegada da família real portuguesa ao Brasil, em 1808, intensificou o fluxo de embarcações e passageiros, aumentando a necessidade de controle sanitário. A partir de 1889, os estados passaram a dispor de códigos sanitários próprios. Em 1953, foi criado o Ministério da Saúde. Na década de 1960, eventos negativos, como a contaminação de peixes com mercúrio, de carne bovina com anabolizantes, e a descoberta de que o consumo do medicamento talidomida pelas mães causava efeitos negativos nos bebês, impulsionaram as reformulações de normas reguladoras, nas quais se atribuiu aos fabricantes a responsabilidade pela qualidade dos produtos oferecidos (Costa \& Rozenfeld, 2009; Marchi, 2003).

A Constituição Federal de 1988 definiu, em seu artigo 200, que compete ao Sistema Único de Saúde (SUS) executar as ações de vigilância sanitária e epidemiológica (Constituição da República Federativa do Brasil, 1988). A criação da Agência Nacional de Vigilância Sanitária (ANVISA), em 1999, deu-se, sobretudo, em decorrência da necessidade de restaurar a credibilidade dos produtos brasileiros no mercado internacional, a partir da criação de um órgão de fiscalização forte, independente do governo - em formato de autarquia (Costa \& Rozenfeld, 2009; Marchi, 2003).

A descentralização das ações de Vigilância Sanitária no município em questão teve seu primeiro passo em 1993, com recursos humanos que somavam cinco técnicos e atividades que se resumiam ao atendimento de denúncias relativas a esgoto, lixo e criação irregular de animais. Ao longo do tempo, houve ampliação da estrutura, a criação do Sistema de Informação de Vigilância Sanitária e do Código Sanitário municipal, a partir de parcerias com outras organizações do governo federal (Silveira, 1999). No final dos anos 1990, ocorreu a municipalização das atividades de controle de alimentos, saneamento e saúde do trabalhador (Silveira, 1999). Analisando a vigilância sanitária do Município, no início dos anos 2000, Marchi (2003) já observava tendências que reproduziam a mesma dinâmica das vigilâncias sanitárias estadual e federal, de caráter jurídico-normativo, repressor, com forte hierarquia. A participação dos usuários limitava-se à possibilidade de apresentar denúncias, nem sempre respondidas.

No ano de 2008, com a Gerência de Vigilância Sanitária já subordinada à Diretoria de Vigilância em Saúde, o número de técnicos mais que dobrou, a partir de um concurso público, possibilitando a ampliação das ações de vigilância sanitária e vigilância em saúde. As ações de aproximação com cidadão e comunidades continuaram, porém, da mesma forma - através do atendimento, por vezes precário, de denúncias.

No ano de 2013, a partir da discussão dos conceitos de promoção de saúde e da proposta de atuação da vigilância em saúde com diversos servidores, uma maneira diferente de pensar o trabalho começou a tomar forma para alguns gestores do setor, com mais abertura para o envolvimento dos usuários e das comunidades em diferentes etapas do processo.

A promoção de saúde é entendida como: "o processo de capacitação da comunidade para atuar na melhoria da sua qualidade de vida e saúde, incluindo uma maior participação no controle desse processo" (Ministério da Saúde, 2002, p. 1). Já a vigilância em saúde é a proposta brasileira para articular as práticas de promoção de saúde com as de prevenção de riscos e agravos (Teixeira \& Solla, 2006). 
A Gerência de Vigilância Sanitária do Município tem, atualmente, como missão, "proteger e promover saúde por meio do controle do risco sanitário" e visão: "romper com o paradigma fiscalizatório-repressor, de modo a não apenas proteger, mas também promover saúde, tornando-se uma referência nacional de vigilância sanitária contemporânea" (Prefeitura de Florianópolis, n.d.).

A definição de vigilância sanitária está contida no artigo $6^{\circ}$, parágrafo $1^{\circ}$, da Lei Federal 8.080 de 1990, que afirma ser a Vigilância Sanitária:

um conjunto de ações capaz de eliminar, diminuir ou prevenir riscos à saúde e de intervir nos problemas sanitários decorrentes do meio ambiente, da produção e circulação de bens e da prestação de serviços de interesse da saúde, abrangendo o controle de bens de consumo que, direta ou indiretamente, se relacionem com a saúde, compreendidas todas as etapas e processos, da produção ao consumo; e o controle da prestação de serviços que se relacionam direta ou indiretamente com a saúde (Lei n. 8.080, 1990, art. 6).

No momento atual, as questões ligadas à qualidade sanitária dos alimentos, com ênfase na importância da vigilância sanitária para a proteção à saúde do consumidor, têm tido destaque nas políticas públicas que tratam de alimentação. Necessita-se de novas formas de enfrentar os desafios decorrentes das transições epidemiológica, nutricional e demográfica do Brasil, que ainda conta com situações de desnutrição, mas também com altas prevalências de sobrepeso e obesidade (Recine \& Vasconcellos, 2011).

\section{Diagnóstico da Situação Problema}

Ainda que ações pontuais de coprodução de serviços públicos e/ou promoção de saúde estejam em desenvolvimento na Gerência de Vigilância Sanitária do Município, como a formação de uma rede que apoie o desenvolvimento de agricultura urbana e a articulação com outras organizações públicas e da sociedade para a formação do Conselho de Segurança Alimentar e Nutricional Sustentável municipal, faz-se necessário avançar no desenho e na implementação de novas possibilidades.

O prolongamento da vida trouxe em si novos problemas sanitários: de um lado, o aumento das DCNT, próprio do processo natural de envelhecimento biológico; de outro, um aumento da exposição aos fatores e situações de risco típicas da sociedade moderna, marcada pela industrialização e pela urbanização (Carvalho, 1996). Nos dias atuais, amplia-se a abrangência da vigilância sanitária em torno das noções de qualidade de vida, promoção da saúde e construção da cidadania. Assim, é interessante desenvolver as ações de fiscalização e, também, as de comunicação e de educação, fundamentais para a democratização do conhecimento (Costa \& Rozenfeld, 2009).

A concepção atualmente difundida de promoção da saúde surgiu e se desenvolveu no Canadá, nos Estados Unidos e em países da Europa ocidental. A formulação do conceito e seus desdobramentos tiveram um marco importante: a Conferência de Ottawa, em 1986 (Teixeira \& Solla, 2006). A Carta de Ottawa, documento construído na Conferência, define promoção da saúde como "o processo de capacitação da comunidade para atuar na melhoria da sua qualidade de vida e saúde, incluindo uma maior participação no controle deste processo" (Ministério da Saúde, 2002, p. 19).

A Carta de Ottawa cita que o ambiente em que se vive e onde se convive é importante para as condições de saúde da população; que medidas adotadas em outros setores costumam influenciar na saúde e; que a sociedade é capaz de realizar ações no sentido de promover saúde e deve fazê-lo (Carvalho, 1996).

A Assembleia da Organização das Nações Unidas (ONU), realizada em setembro de 2011, afirmou que as DCNT e o impacto que trazem são um dos grandes desafios a serem enfrentados no século XXI. Além disso, enfatizou a responsabilidade dos governos em responder a esse desafio, contando com a participação de outros setores na prevenção e controle das DCNT. As ações de 
promoção de saúde geralmente vão além do setor saúde, demandando engajamento e articulação entre diferentes níveis e órgãos de governo, empresas e sociedade civil (Duncan et al., 2012; Malta et al., 2014).

Apesar de os países e áreas de administração pública diferirem na extensão do papel dos cidadãos na provisão de serviços públicos, a ideia de coprodução, na qual as instituições públicas não são as únicas responsáveis pela provisão, está ganhando força ao redor do mundo. Além disso, existem muitas tarefas complexas do setor público que não podem ser cumpridas sem que os indivíduos coloquem seus esforços e recursos, e trabalhem de maneira articulada, principalmente em setores como saúde, educação, meio ambiente e segurança pública, já que é impossível entregar os serviços sem contribuições de tempo e esforço dos próprios usuários (Fung, 2006; Pestoff, 2009; Poocharoen \& Ting, 2015).

A ideia de coprodução de serviços públicos foi articulada pela primeira vez pela economista Elinor Ostrom e seu grupo na Universidade de Indiana, nos anos 1970 (Boyle \& Harris, 2009). No Brasil, o tema ainda é pouco disseminado, embora sejam estudadas diversas práticas relacionadas à coprodução nas interfaces entre administração pública, participação cidadã, terceiro setor, gestão social, inovação social e responsabilidade social empresarial (Salm, Schommer, Heidemann, Vendramini, \& Menegasso, 2011).

A coprodução de serviços públicos consiste no desenho, no planejamento, na realização, na entrega e/ou na avaliação de um serviço público por atores externos à organização pública, em conjunto com os servidores públicos (Bovaird, 2007; Bovaird \& Loeffler, 2012; Palumbo, 2016; Pestoff, 2009; Schommer, Andion, Pinheiro, Spaniol, \& Serafim, 2011). Bovaird (2007) definiu coprodução como a provisão de serviços públicos por relações regulares e de longo prazo entre os provedores profissionais do serviço e os usuários ou outros membros da comunidade, onde todas as partes fazem substanciais contribuições.

Os usuários dos serviços públicos, ou mesmo a comunidade em geral, são tradicionalmente vistos como uma categoria passiva de atores no processo de elaboração de políticas públicas (Secchi, 2013). Crescentemente se percebe que os usuários do serviço são essenciais para fazê-lo funcionar. Nesse tipo de processo, os servidores públicos precisam mudar a maneira de realizar suas atividades e estar preparados para confiar nas decisões dos usuários e da comunidade, que se tornam seus parceiros (Bovaird, 2007; Bovaird \& Loeffler, 2012; Boyle \& Harris, 2009).

Inúmeras vantagens na aplicação de processos de coprodução de serviços públicos são citadas por estudiosos do tema, dentre elas a resposta mais adequada às necessidades e desejos do cidadão; o ganho em eficiência e efetividade dos serviços; os novos conhecimentos e o desenvolvimento de múltiplas capacidades e habilidades de cidadania, que levam ao empoderamento do cidadão; aumento do senso de pertencimento a uma comunidade e maior engajamento cidadão em várias outras atividades; redistribuição e compartilhamento de poder entre profissionais e cidadãos; ampliação das possibilidades de inovação nos serviços públicos e; o aumento da legitimidade das ações coproduzidas, já que esse tipo de processo melhora a confiança pública no governo, o que contribui para a preservação e para a continuidade das políticas públicas (Bovaird, 2007; Boyle \& Harris, 2009; Fung, 2006; Klein, Salm, Heidemann, \& Menegasso, 2012; Palumbo, 2016; Roberts, 2004; Schommer et al., 2011).

Conforme observado por Ostrom (1996), a sinergia nas relações de coprodução potencialmente agrega valor ao produto ou serviço. Adição de valor que vem sendo estudada por Bovaird e Loefler (2012), Osborne, Radnor e Strokosch (2016), em variados formatos e diferentes bens e serviços públicos, buscando compreender as condições e as características que a favorecem ou a dificultam.

As ações de coprodução em serviços de saúde alinham-se com o conceito de promoção da saúde, que chama atenção para a necessidade de incluir diferentes atores, inclusive os usuários e sua comunidade, no desenvolvimento da saúde (Marston et al., 2016).

No que tange aos hábitos alimentares, um dos focos da promoção da saúde, tem ocorrido no Brasil um substancial aumento no número de refeições realizadas fora de casa desde o ano 2000. A pesquisa 
de orçamento familiar de 2008/2009 demonstrou que $40 \%$ da população realiza alguma refeição fora de casa diariamente (IBGE, 2010). Tal aumento pode ser justificado por dificuldades impostas pelos deslocamentos; jornadas de trabalho extensas; escassez de tempo para preparo e consumo de alimentos; e o crescimento da quantidade de mulheres no mercado de trabalho, aumentando, assim, o número de estabelecimentos de alimentação disponíveis (French, Story, \& Jeffery, 2001; Garcia, 2003; Veiros, Proença, Kent-Smith, Hering, \& Sousa, 2006).

Ao comer fora de casa, porém, os hábitos saudáveis são ignorados por muitas pessoas. Uma vez que essas refeições compreendem uma grande porção do total de energia ingerido em um dia, sua qualidade nutricional torna-se um fator de risco para a saúde (French et al., 2001; Veiros et al., 2006). A escolha do alimento a ser consumido é um processo que envolve múltiplas variáveis, sendo mais complexo do que simplesmente comer para saciar a fome, já que outros fatores podem competir com a vontade de comer de forma saudável (Furst et al., 1996).

De acordo com a Organização Mundial da Saúde (OMS, 2015), ambientes e comunidades que sustentam hábitos saudáveis são fundamentais para moldar as escolhas das pessoas e prevenir a obesidade. Políticas de saúde que criam ambientes que favorecem escolhas saudáveis são essenciais para motivar as pessoas a adotarem comportamentos saudáveis.

Visando partilhar a elaboração, a implementação e a avaliação dessas políticas, governos têm chamado cidadãos e organizações para participar da melhoria da qualidade dos serviços de saúde, porém, são mais comuns situações em que são solicitados apenas para opinar, não para participar de construção colaborativa. Muitos profissionais de saúde ainda se mostram apreensivos em relação a essa nova maneira de trabalhar, já que pode ser necessária mudança na hierarquia, no compartilhamento de poder e no aprendizado (Renedo, Marston, Spyridonidis, \& Barlow, 2015).

Considerados esses elementos, entende-se: que a criação de ambientes saudáveis e o empoderamento do cidadão para fazer suas próprias escolhas são caminhos para as ações de promoção de saúde; que o governo não detém todo o conhecimento e pode ser facilitador de um processo de construção compartilhada de saberes; que as políticas públicas coproduzidas com os interessados potencialmente atingem resultados mais eficazes; que parte da população do município estudado tem o hábito de realizar as principais refeições fora de casa; a criação de um instrumento que identifique, para a população em geral, os serviços de alimentação que oferecem alimentos saudáveis, deve facilitar a escolha individual e criar uma movimentação dos estabelecimentos comerciais de alimentos, no sentido de melhorar a qualidade nutricional das refeições por eles oferecidas. Esse é o desafio (e a possibilidade) que orienta a construção desse trabalho.

\section{Desenvolvimento da Proposta de Intervenção}

A abordagem metodológica escolhida para a realização do trabalho foi a design science, que pode ser definida como o desenvolvimento de conhecimento para o desenho de mecanismos a serem utilizados em soluções para problemas, fazendo a conexão entre o mundo teórico e o prático (Aken, 2004; Jelinek et al., 2008).

Foi elaborada uma proposta de ação para enfrentamento do problema das DCNT a ser realizado pela vigilância sanitária de alimentos do Município, em coprodução com outros atores. Dessa forma, foi iniciado o trabalho prático, em uma pesquisa interativa, com expectativa de certos resultados e possibilidade de resultados inesperados.

Estabeleceu-se, inicialmente, um cronograma de seis encontros presenciais entre os atores convidados a participar, com início em outubro de 2015 e previsão de término em março de 2016, com horários e datas a serem agendados de acordo com a preferência dos participantes. Os primeiros convidados foram os fiscais de vigilância em saúde que desenvolviam suas atividades na vigilância sanitária de alimentos e os órgãos de representação da classe de nutricionistas. Isso em função da 
necessidade de agregar os conhecimentos técnicos dos fiscais e nutricionistas, e iniciar um delineamento mais detalhado da proposta, com base nos conhecimentos científicos de quais os principais fatores da alimentação que são fatores de risco ou protetores das DCNT. Em seguida, assim que os participantes iniciais julgassem apropriado, os órgãos de representação dos restaurantes e os cidadãos consumidores de restaurantes em formato bufê seriam chamados.

A pesquisadora participou principalmente como organizadora e mediadora dos encontros, porém livre para opinar a partir de seus conhecimentos técnicos como fiscal de vigilância em saúde, coordenadora de fiscalização sanitária e nutricionista. As pautas foram deixadas livres, a depender do desenrolar das reuniões e dos resultados de cada etapa, sugerindo-se inicialmente perguntas a serem respondidas ao longo do processo, dentre elas:

Tabela 1

\section{Perguntas para Responder ao longo do Processo}

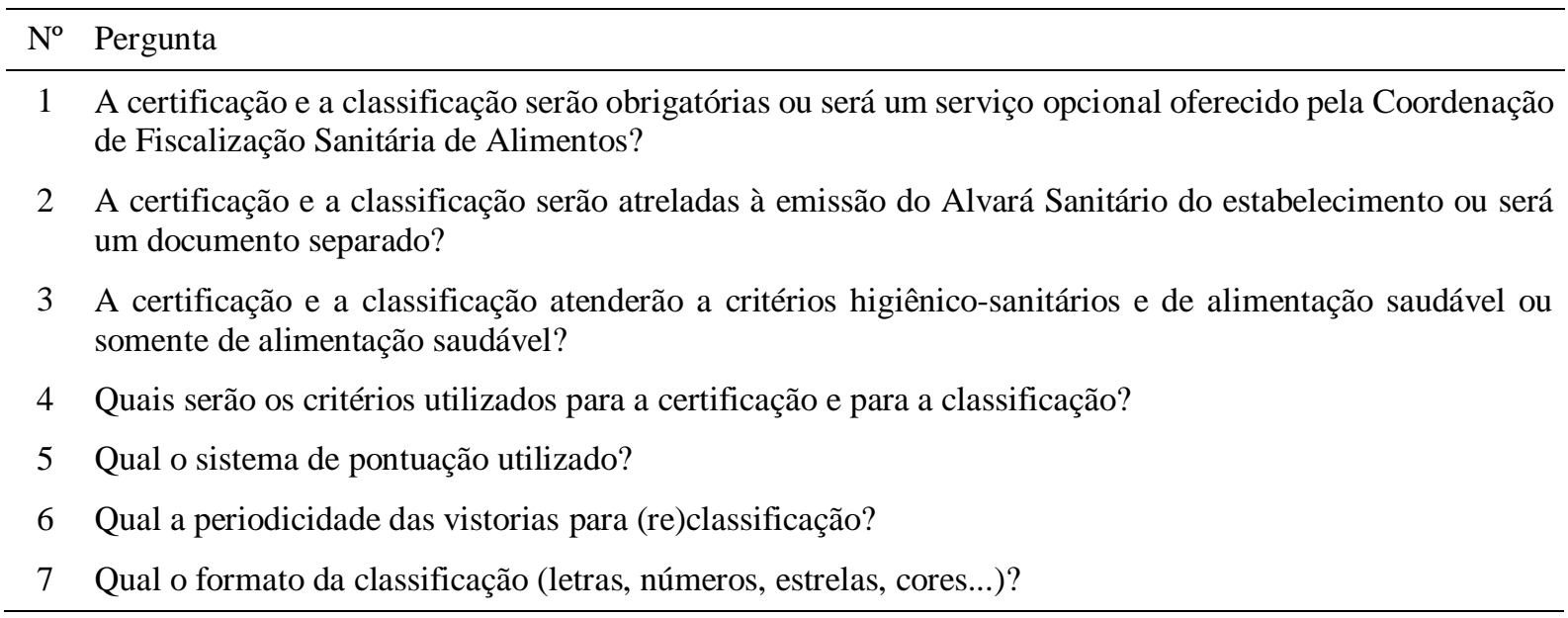

Nota. Fonte: Elaborada pelas autoras.

Como produto final desse processo, esperava-se obter, de forma coproduzida com atores externos à organização especialista em fiscalização (a vigilância sanitária do Município), o roteiro de inspeção com os critérios a serem utilizados para certificar e classificar os estabelecimentos, assim como o símbolo da Certificação e Classificação em Qualidade Nutricional por avaliação dos alimentos servidos.

Nesse trabalho, aplicou-se o conceito mais abrangente de coprodução, ou modelo aprimorado, segundo Osborne e Strokosh (2013), que inclui usuários, a comunidade e outras organizações, participando já a partir do planejamento do serviço e, posteriormente, também na entrega ou implementação, aumentando seu potencial de inovação.

Os convites aos participantes foram realizados a partir de uma carta-convite contendo explicação sobre o projeto e seus objetivos e data do próximo encontro, que foi enviada por e-mail às entidades, com duas semanas de antecedência. Também foram realizados contatos por telefone para incentivar as confirmações de participação. Quanto aos fiscais, as cartas foram entregues pessoalmente, pela pesquisadora, no momento em que explicava detalhadamente do que se tratava o projeto e como seria a atuação dos fiscais no mesmo (em horário regular de trabalho, trazendo os conhecimentos de fiscalização), por mais que nem todos fossem graduados em cursos da área da saúde ou nutrição. A Tabela 2 demonstra, resumidamente, como se desenvolveram os encontros. 
Tabela 2

Resumo dos Encontros do Grupo de Trabalho para Certificação e Classificação de Restaurantes

\begin{tabular}{|c|c|c|c|c|c|}
\hline $\mathrm{N}^{\mathrm{o}}$. & Data & Objetivos & Participantes & Resultados & Observações Gerais \\
\hline 1 & $27 / 10 / 15$ & $\begin{array}{l}\text { Apresentar a proposta } \\
\text { de trabalho para fiscais } \\
\text { e técnicos convidados; } \\
\text { Formar o Grupo de } \\
\text { Trabalho com agenda } \\
\text { definida. }\end{array}$ & $\begin{array}{l}\text { A pesquisadora; } \\
6 \text { nutricionistas } \\
\text { representando } \\
\text { entidades } \\
\text { convidadas; } \\
1 \text { fiscal de } \\
\text { vigilância em } \\
\text { saúde; } \\
\text { A professora } \\
\text { orientadora da } \\
\text { pesquisa. }\end{array}$ & $\begin{array}{l}\text { Adesão dos } \\
\text { convidados ao Grupo } \\
\text { de Trabalho; } \\
\text { Agenda para os } \\
\text { próximos encontros. }\end{array}$ & $\begin{array}{l}\text { Os presentes se mostraram } \\
\text { muito interessados na } \\
\text { proposta. } \\
\text { Dois dos fiscais que } \\
\text { haviam concordado em } \\
\text { participar do Grupo de } \\
\text { Trabalho não } \\
\text { compareceram à reunião. }\end{array}$ \\
\hline 2 & $11 / 11 / 15$ & $\begin{array}{l}\text { Alinhar as expectativas } \\
\text { dos participantes com o } \\
\text { projeto; } \\
\text { Discutir possíveis } \\
\text { critérios para avaliar a } \\
\text { qualidade nutricional } \\
\text { dos alimentos servidos } \\
\text { em restaurantes tipo } \\
\text { bufê. }\end{array}$ & $\begin{array}{l}\text { A pesquisadora; } \\
5 \text { nutricionistas } \\
\text { representando } \\
\text { entidades } \\
\text { convidadas; } \\
3 \text { fiscais de } \\
\text { vigilância em } \\
\text { saúde; } \\
\text { A professora } \\
\text { orientadora da } \\
\text { pesquisa. }\end{array}$ & $\begin{array}{l}\text { Avaliação da } \\
\text { qualidade nutricional } \\
\text { dividida em cinco } \\
\text { etapas; } \\
\text { Definição de alguns } \\
\text { critérios; } \\
\text { Percepção da } \\
\text { necessidade de } \\
\text { pesquisar estudos } \\
\text { afins ao tema } \\
\text { discutido. }\end{array}$ & $\begin{array}{l}\text { Definiu-se que seriam } \\
\text { necessários mais encontros } \\
\text { entre técnicos e fiscais } \\
\text { antes do convite para } \\
\text { outros participantes. }\end{array}$ \\
\hline 3 & $25 / 11 / 15$ & $\begin{array}{l}\text { Apresentar estudos } \\
\text { afins ao tema discutido; } \\
\text { Definir critérios de } \\
\text { cada etapa da } \\
\text { avaliação. }\end{array}$ & $\begin{array}{l}\text { A pesquisadora; } \\
2 \text { nutricionistas } \\
\text { representando } \\
\text { entidades } \\
\text { convidadas; } \\
2 \text { fiscais de } \\
\text { vigilância em } \\
\text { saúde. }\end{array}$ & $\begin{array}{l}\text { Critérios definidos } \\
\text { detalhadamente. }\end{array}$ & $\begin{array}{l}\text { Muitos convidados não } \\
\text { compareceram ao } \\
\text { encontro, dentre esses, } \\
\text { dois participantes } \\
\text { deixaram o grupo de forma } \\
\text { definitiva, um por não se } \\
\text { sentir contribuindo e outra } \\
\text { por impedimentos } \\
\text { pessoais. }\end{array}$ \\
\hline 4 & $09 / 12 / 15$ & $\begin{array}{l}\text { Separar os critérios em } \\
\text { indispensáveis ou não, } \\
\text { para a certificação. }\end{array}$ & $\begin{array}{l}\text { A pesquisadora; } \\
4 \text { nutricionistas } \\
\text { representando } \\
\text { entidades } \\
\text { convidadas; } \\
2 \text { fiscais de } \\
\text { vigilância em } \\
\text { saúde. }\end{array}$ & $\begin{array}{l}\text { Discussão sobre } \\
\text { alguns critérios mais } \\
\text { polêmicos; } \\
\text { Separação dos } \\
\text { critérios em } \\
\text { indispensáveis ou } \\
\text { não. }\end{array}$ & $\begin{array}{l}\text { Maior comparecimento de } \\
\text { atores técnicos ao } \\
\text { encontro, decisão dos } \\
\text { participantes de convidar } \\
\text { as representações de } \\
\text { restaurantes para o } \\
\text { próximo encontro. }\end{array}$ \\
\hline
\end{tabular}


Tabela 2 (continuação)

\begin{tabular}{|c|c|c|c|c|c|}
\hline $\mathrm{N}^{\mathrm{o}}$. & Data & Objetivos & Participantes & Resultados & Observações Gerais \\
\hline 5 & $03 / 03 / 16$ & $\begin{array}{l}\text { Discutir os critérios } \\
\text { com as } \\
\text { representações de } \\
\text { restaurantes; } \\
\text { Pontuar os critérios } \\
\text { para a classificação } \\
\text { de acordo com a } \\
\text { qualidade } \\
\text { nutricional. }\end{array}$ & $\begin{array}{l}\text { A pesquisadora; } \\
1 \text { nutricionista } \\
\text { representando } \\
\text { entidades } \\
\text { convidadas; } \\
1 \text { fiscal de } \\
\text { vigilância em } \\
\text { saúde; } \\
\text { A professora } \\
\text { orientadora da } \\
\text { pesquisa. }\end{array}$ & $\begin{array}{l}\text { Pontuação dos } \\
\text { critérios para a } \\
\text { classificação, de } \\
\text { acordo com a } \\
\text { qualidade nutricional. }\end{array}$ & $\begin{array}{l}\text { As representações de } \\
\text { restaurantes não compareceram } \\
\text { ao encontro. } \\
\text { Mais uma participante deixou o } \\
\text { grupo definitivamente por } \\
\text { impedimentos pessoais. } \\
\text { Definiu-se que o roteiro seria } \\
\text { testado em restaurantes do } \\
\text { município pelos fiscais de } \\
\text { vigilância em saúde atuantes na } \\
\text { Coordenação de Fiscalização } \\
\text { Sanitária de Alimentos. }\end{array}$ \\
\hline 6 & $07 / 04 / 16$ & $\begin{array}{l}\text { Repassar as } \\
\text { impressões dos } \\
\text { fiscais na aplicação } \\
\text { do roteiro; } \\
\text { Finalizar o roteiro; } \\
\text { Discutir como } \\
\text { incluir } \\
\text { representações de } \\
\text { restaurantes e } \\
\text { cidadãos no Grupo } \\
\text { de Trabalho. }\end{array}$ & $\begin{array}{l}\text { A pesquisadora; } \\
2 \text { nutricionistas } \\
\text { representando } \\
\text { entidades } \\
\text { convidadas; } \\
1 \text { fiscal de } \\
\text { vigilância em } \\
\text { saúde. }\end{array}$ & $\begin{array}{l}\text { Finalização do roteiro } \\
\text { a partir das } \\
\text { observações dos oito } \\
\text { fiscais que aplicaram } \\
\text { o roteiro para teste; } \\
\text { Decisão por convidar } \\
\text { diretamente gestores } \\
\text { de restaurantes, } \\
\text { representação de } \\
\text { consumidores e } \\
\text { outros consumidores, } \\
\text { diretamente, para o } \\
\text { próximo encontro. }\end{array}$ & $\begin{array}{l}\text { A representação de restaurantes } \\
\text { que ainda mantinha contato não } \\
\text { compareceu à reunião. }\end{array}$ \\
\hline 7 & $25 / 04 / 16$ & $\begin{array}{l}\text { Apresentar a } \\
\text { proposta de trabalho } \\
\text { para os novos } \\
\text { participantes; } \\
\text { Discutir aspectos } \\
\text { gerais da } \\
\text { certificação e } \\
\text { classificação, como } \\
\text { a periodicidade das } \\
\text { vistorias e prazos } \\
\text { para adequação; } \\
\text { Discutir e definir } \\
\text { quais símbolos } \\
\text { representarão a } \\
\text { certificação e a } \\
\text { classificação dos } \\
\text { restaurantes. }\end{array}$ & $\begin{array}{l}\text { A pesquisadora; } \\
1 \text { nutricionista } \\
\text { representando } \\
\text { entidades } \\
\text { convidadas; } \\
1 \text { fiscal de } \\
\text { vigilância em } \\
\text { saúde; } \\
\text { A professora } \\
\text { orientadora da } \\
\text { pesquisa; } \\
8 \text { gestores de } \\
\text { restaurantes; } \\
1 \text { consumidora. }\end{array}$ & $\begin{array}{l}\text { Definição de aspectos } \\
\text { gerais da certificação } \\
\text { e classificação; } \\
\text { Percepção de que } \\
\text { deve haver outros } \\
\text { encontros para } \\
\text { discussão dos } \\
\text { critérios de } \\
\text { certificação e } \\
\text { classificação com os } \\
\text { gestores de } \\
\text { restaurantes; } \\
\text { Sugestão de alguns } \\
\text { símbolos para a } \\
\text { certificação e a } \\
\text { classificação. }\end{array}$ & $\begin{array}{l}\text { A representação dos } \\
\text { consumidores não compareceu } \\
\text { à reunião. Entre consumidores } \\
\text { convidados diretamente, } \\
\text { somente uma compareceu. Os } \\
\text { gestores de restaurantes } \\
\text { convidados diretamente } \\
\text { compareceram em grande } \\
\text { número. As sugestões de } \\
\text { símbolos foram ricas. Definiu- } \\
\text { se por aguardar a elaboração do } \\
\text { símbolo por profissional, de } \\
\text { acordo com o direcionamento } \\
\text { dado na reunião, para posterior } \\
\text { escolha através de mensagens } \\
\text { de } e \text {-mail. }\end{array}$ \\
\hline
\end{tabular}

Nota. Fonte: Elaborada pelas autoras.

O processo de unir servidores públicos, técnicos, cidadãos e representações de segmentos organizados em torno de um objetivo não pode ser nada menos que complexo. Ao término, porém, sentiu-se mais segurança com o resultado, afinal uma construção conjunta com os principais interessados parece ter muito mais chances de ser bem-sucedida, já que adiciona valores como: combinação de diversos conhecimentos técnicos e experiências; elaboração de instrumento de utilização factível, pois condiz com a capacidade da fiscalização e dos estabelecimentos regulados; legitimidade da ação. A Figura 1 demonstra o fluxo do processo. 


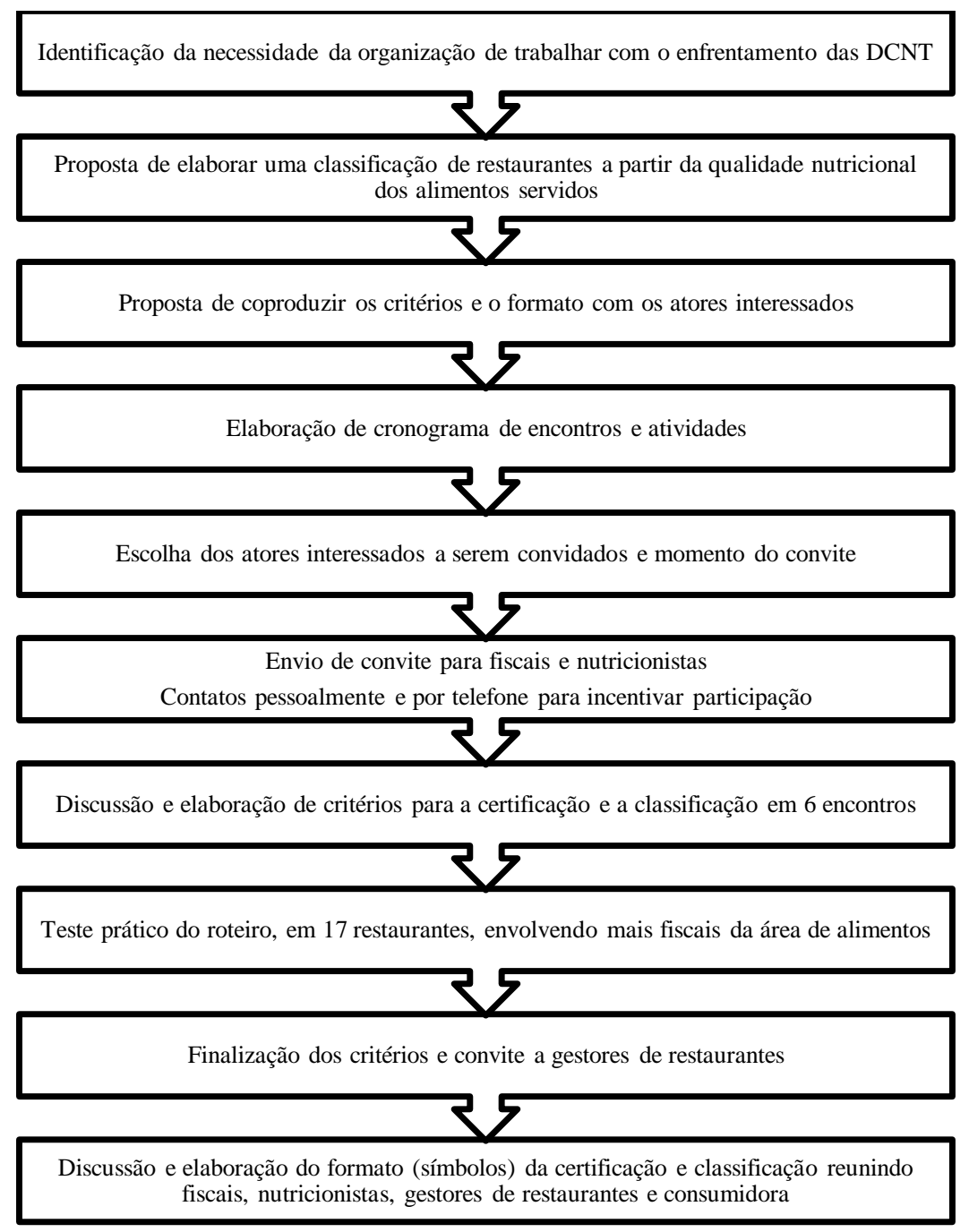

Figura 1. Fluxo do Processo de Elaboração da Certificação e Classificação de Restaurantes Fonte: Elaborada pelas autoras.

As dificuldades ocorreram ao longo de todo o período, iniciando com a negativa de participação de alguns dos fiscais convidados, que não acreditaram que poderiam contribuir com o trabalho naquele momento, principalmente por não serem graduados em cursos da área da saúde. Além disso, a participação de poucas pessoas em algumas reuniões, por fatores como a falta de tempo na rotina atual, agravada pela dificuldade de trafegar entre um lugar e outro em determinados horários.

A ausência da associação e do sindicato de representação dos restaurantes foi marcante. Apesar da insistência e da importância do projeto para os estabelecimentos que essas representam, elas não se fizeram presentes em momento algum. Talvez por desacreditar que o projeto fosse levado adiante, ou, no caso da associação que justificou a ausência, falta de representantes e de agenda. A confirmação de presença para os encontros, porém, fez com que os convites diretos a gestores de restaurantes fossem adiados, limitando sua participação ao último encontro.

Os consumidores, praticamente ausentes nos encontros, não demonstraram interesse em participar, apesar do tema de alimentação saudável estar popularizado e de haver oferta de sorteio de brindes nas reuniões. Mesmo a representação de cidadãos, o Conselho Municipal de Segurança Alimentar e Nutricional Sustentável (COMSEAS), não conseguiu viabilizar a presença de representantes. Isso mostra a necessidade de outra abordagem e novos instrumentos para que os consumidores participem do processo. 
Já a participação dos fiscais e dos técnicos foi satisfatória. Apesar de alguns terem comparecido a somente dois dos sete encontros, outros compareceram a praticamente todos, se interessaram em trazer estudos acerca do tema e fizeram diversas contribuições. Nesse caso, acredita-se que a identificação com o tema e o entendimento de sua importância para a situação epidemiológica da população do Município contribuíram para a participação mais frequente e regular.

O teste realizado com o instrumento, em 17 restaurantes, antes da finalização dos critérios, trouxe importantes impressões para a discussão, como mais confiança para a tomada de decisão e, indiretamente, fazendo com que todos os fiscais que atuavam na fiscalização sanitária de alimentos e restaurantes inspecionados participassem. Apesar de alguns fiscais não terem aceitado participar das reuniões do Grupo de Trabalho, aceitaram de pronto realizar o teste prático, sem grandes alterações nas suas rotinas diárias.

Realizou-se avaliação do Grupo de Trabalho para Classificação de Restaurantes pelos participantes que compareceram a dois ou mais encontros. Os respondentes destacaram como pontos fortes: o formato das reuniões; a reunião de profissionais nutricionistas e profissionais de fiscalização sendo pontos-chave para a discussão do roteiro, esses com perfis e áreas de trabalho diversificadas, que enriqueceram as discussões com visões complementares e agregaram os conhecimentos da academia com o serviço público; o fato de ter havido um intervalo entre um encontro e outro, utilizado para amadurecer algumas ideias e rever alguns entendimentos, possibilitando um resultado mais maduro dos critérios; o envolvimento de representantes dos restaurantes, que tornou o processo de construção conjunto mais interessante e com maiores possibilidades de adesão.

Já como fragilidades e dificuldades no processo, os participantes relataram a dificuldade de agenda, que fez com que estivessem presentes menos pessoas que o esperado, para um processo como esse; a falta de entidades representativas de restaurantes e a dificuldade de acesso a esses; e, a quase ausência de participação dos consumidores, para compreender como receberiam a informação e poderiam se envolver no processo.

Sobre recomendações para futuras iniciativas similares, como construção colaborativa de instrumentos de avaliação e fiscalização, os participantes ressaltaram que o processo, da maneira que foi conduzido, foi adequado. Para amenizar o problema de comprometimento de especialistas e de participação de entidades representativas do segmento regulado e cidadãos, foi sugerido buscar aprimorar a articulação e realizar o processo mais rapidamente.

Ao final do último encontro, os gestores de restaurantes e a consumidora participantes também responderam a duas perguntas de avaliação: Qual sua opinião sobre a classificação de restaurantes de acordo com a qualidade nutricional dos alimentos servidos? e Como você avalia a prática que acabamos de realizar e quais as suas sugestões para outras atividades como essa? A participante representando os consumidores citou que "a ideia é muito interessante para o cliente, pois já saberão o que vão encontrar dependendo da classificação do restaurante". Os representantes de gestores de restaurantes relataram que a proposta deve "agregar valor aos restaurantes que aderirem"; "possibilitar ao consumidor opções de alimentação mais saudável nas refeições fora de casa"; "incentivar os restaurantes a oferecer refeições mais equilibradas"; e que "será uma forma de destacar meu estabelecimento perante os muitos outros". Foi citado que é "muito importante contribuir para um trabalho como esse", em que há abertura pelos servidores públicos para envolvimento dos participantes na prestação do serviço, e que todos puderam ficar à vontade para dialogar.

Durante o trabalho, foram respondidas as perguntas iniciais, conforme demonstrado na Tabela 3 , que detalha o resultado final dos encontros do Grupo de Trabalho - o Roteiro de Inspeção para Certificação e Classificação de Restaurantes, suas divisões, critérios e pontuações, incluído como Apêndice neste trabalho. 
Tabela 3

\section{Perguntas Respondidas ao longo do Processo}

\begin{tabular}{|c|c|c|}
\hline $\mathbf{N}^{\mathbf{o}}$ & Pergunta & Resposta \\
\hline 1 & $\begin{array}{l}\text { A certificação e a classificação serão } \\
\text { obrigatórias ou será um serviço opcional } \\
\text { oferecido pela Coordenação de } \\
\text { Fiscalização Sanitária de Alimentos? }\end{array}$ & $\begin{array}{l}\text { Serão inicialmente serviços opcionais, oferecidos pela Gerência } \\
\text { de Vigilância Sanitária do Município para restaurante no } \\
\text { formato de bufê, mas que tendem a se tornar obrigatórios em } \\
\text { longo prazo. }\end{array}$ \\
\hline 2 & $\begin{array}{l}\text { A certificação e a classificação serão } \\
\text { atreladas à emissão do Alvará Sanitário } \\
\text { do estabelecimento ou será um } \\
\text { documento separado? }\end{array}$ & $\begin{array}{l}\text { Não serão atreladas à emissão do Alvará Sanitário (exatamente } \\
\text { por não serem obrigatórias). }\end{array}$ \\
\hline 3 & $\begin{array}{l}\text { A certificação e a classificação atenderão } \\
\text { a critérios higiênico-sanitários e de } \\
\text { alimentação saudável ou somente de } \\
\text { alimentação saudável? }\end{array}$ & $\begin{array}{l}\text { Atenderão a critérios de qualidade nutricional dos alimentos } \\
\text { servidos pelo estabelecimento. Num primeiro momento, os } \\
\text { restaurantes que cumprirem critérios essenciais serão } \\
\text { certificados e, num segundo momento, serão verificados outros } \\
\text { critérios aos quais se atribuiu pontuação, para classificação em } \\
\text { diferentes níveis de qualidade nutricional. }\end{array}$ \\
\hline
\end{tabular}

4 Quais serão os critérios utilizados para a Os critérios foram divididos em cinco áreas, de acordo com os certificação e para a classificação? momentos da inspeção, totalizando 43 critérios. Esses levam em consideração utensílios e equipamentos disponíveis, matérias-primas utilizadas, modos de preparo, informações disponíveis ao consumidor, dentre outros.

5 Qual o sistema de pontuação utilizado? A pontuação variará de 8 pontos positivos a 6 pontos negativos, dependendo do critério, para critérios de classificação. Os critérios de certificação não têm pontuação atribuída, são obrigatórios.

6 Qual a periodicidade das vistorias para (re)classificação?

A periodicidade das vistorias para mudança de classificação será a cada ano, inicialmente, porém pode ocorrer a qualquer momento para verificação do cumprimento dos critérios e para atendimento de denúncias relativas ao tema.

7 Qual o formato da classificação (letras, números, estrelas, cores...)?

O símbolo da certificação e da classificação de restaurantes, construído com a contribuição de todos os participantes, contém a imagem de um prato, garfo e faca, o rótulo "Certificação de Qualidade Nutricional" e estrelas logo abaixo da imagem, que identificam a classificação em 3, 4 ou 5 estrelas.

Nota. Fonte: Elaborada pelas autoras. 


\section{Conclusões e Contribuição Tecnológica e Social}

As políticas que trabalham o ambiente em que as pessoas vivem e não somente suas escolhas individuais têm maiores chances de modificar hábitos. A coprodução é uma abordagem que potencialmente aumenta a qualidade, a eficiência e a legitimidade dos serviços públicos, podendo ser aplicada do planejamento à entrega do serviço. O estudo propôs-se a explorar o tema das DCNT na Coordenação de Fiscalização Sanitária de Alimentos a partir de uma proposta coproduzida por servidores públicos, técnicos, estabelecimentos regulados e cidadãos consumidores.

As demais coordenações de fiscalização da Gerência de Vigilância Sanitária, assim como outros setores, gerências e diretorias da Secretaria Municipal de Saúde e da Prefeitura, poderão utilizar-se dos conhecimentos obtidos neste projeto e iniciar outros trabalhos de coprodução do planejamento de ações de fiscalização e na fiscalização em si, em conjunto com os maiores interessados: os estabelecimentos e profissionais que são regulados, os consumidores desses produtos e serviços e a população do município como um todo. Ainda, outras organizações que trabalham a fiscalização de alimentos e queiram utilizar-se da experiência para criar seus próprios roteiros poderão utilizar este trabalho como referência.

O trabalho foi limitado em não sistematizar randomicamente os convites às organizações, representações e cidadãos, podendo gerar um viés nas opiniões, de acordo com características particulares. Além de não testar outras abordagens, além do convite e oferecimento de brindes, para atrair os usuários como participantes para a construção do trabalho.

Sugere-se que futuros trabalhos para construção de instrumentos de fiscalização e/ou certificação de estabelecimentos realizem teste durante a elaboração dos mesmos, como o realizado nesse trabalho, o que garante mais confiança na escolha dos critérios. Bem como trabalhos quaisquer que envolvam a coprodução de serviços públicos e desenvolvam abordagens variadas para atrair e manter o envolvimento de atores-chave.

O próximo passo para a vigilância sanitária do Município, prosseguindo com apoio dos envolvidos na elaboração do instrumento, será regulamentar e implementar a certificação e classificação dos estabelecimentos, divulgando-a amplamente. Nessa nova etapa, será necessário envolver ainda outros segmentos, possivelmente criando uma comissão (co-comissioning) para monitorar a implementação e aprimorar continuamente o processo. É importante que todos os envolvidos compreendam e se envolvam de alguma maneira para que a Certificação e a Classificação em Qualidade Nutricional efetivamente contribuam para a qualidade dos alimentos e as escolhas relativas à saúde dos cidadãos.

\section{Referências}

Aken, J. E., van (2004). Management research based on the paradigm of the design sciences: the quest for field-tested and grounded technological rules. Journal of Management Studies, 41(2), 219246. http://dx.doi.org/10.1111/j.1467-6486.2004.00430.x

Bovaird, T. (2007). Beyond engagement and participation: user and community coproduction of public services. Public Administration Review, 67(5), 846-860. http://dx.doi.org/10.1111/j.15406210.2007.00773.x

Bovaird, T., \& Loeffler, E. (2012). From engagement to co-production: the contribution of users and communities to outcomes and public value. International Journal of Voluntary and Nonprofit Organizations, 23(4), 1119-1138. http://dx.doi.org/10.1007/s11266-012-9309-6 
Boyle, D., \& Harris, M. (2009). The challenge of co-production - How equal partnerships between professionals and the public are crucial to improving public services [Discussion Paper]. NESTA, New Economic Foundation, The Lab, London, UK. Recuperado de http://www.nesta.org.uk/sites/default/files/the_challenge_of_co-production.pdf

Buss, P. M., \& Carvalho, A. I. de (2009). Desenvolvimento da promoção da saúde no Brasil nos últimos vinte anos (1988-2008). Ciência \& Saúde Coletiva, 14(6), 2305-2316. http://dx.doi.org/10.1590/S1413-81232009000600039

Carvalho, A. I. de (1996). Da saúde pública às políticas saudáveis - saúde e cidadania na pósmodernidade. Ciência \& Saúde Coletiva, 1(1), 104-121. http://dx.doi.org/10.1590/1413812319961101572014

Constituição da República Federativa do Brasil de 1988. (1988). Recuperado de http://www.planalto.gov.br/ccivil_03/Constituicao/Constituicao.htm

Costa, E. A., \& Rozenfeld, S. (2009). Constituição da vigilância sanitária no Brasil. In S. Rozenfeld (Org.), Fundamentos da vigilância sanitária (6a ed., pp. 15-40). Rio de Janeiro: Editora Fiocruz.

Departamento de Atenção Básica. (n.d.). Estratégia saúde da família. Recuperado em 10 fevereiro, 2015, de http://dab.saude.gov.br/portaldab/ape_esf.php

Duncan, B. B., Chor, D., Aquino, E. M., Bensenor, I. M., Mill, J. G., Schmidt, M. I., Lotufo, P. A., Vigo, A., \& Barreto, S. M. (2012). Doenças crônicas não transmissíveis no Brasil: prioridade para enfrentamento e investigação. Revista de Saúde Pública, 46(s1), 126-134. http://dx.doi.org/10.1590/S0034-89102012000700017

Food Standards Agency. (2015, January 26). Frequently asked questions about the food hygiene rating scheme. Recuperado em 09 setembro, 2015, de http://www.food.gov.uk/multimedia/hygienerating-schemes/ratings-find-out-more-en/fhrs

French, S. A., Story, M., \& Jeffery, R. W. (2001). Environmental influences on eating and physical activity. Annual Review of Public Health, 22(1), 309-335. https://dx.doi.org/10.1146/annurev.publhealth.22.1.309

Fundo Nacional de Desenvolvimento da Educação. (n.d.). Sobre o PNAE. Recuperado em 11 fevereiro, 2015, de http://www.fnde.gov.br/programas/alimentacao-escolar

Fung, A. (2006). Varieties of participation in complex governance. Public Administration Review, 66(s1), 66-75. http://dx.doi.org/10.1111/j.1540-6210.2006.00667.x

Furst, T., Connors, M., Bisogni, C. A., Sobal, J., \& Falk, L. W. (1996). Food choice: a conceptual model of the process. Appetite, 26(3), 247-266. http://dx.doi.org/10.1006/appe.1996.0019

Garcia, R. W. D. (2003). Reflexos da globalização na cultura alimentar: considerações sobre as mudanças na alimentação urbana. Revista de Nutrição, 16(4), 483-492. https://dx.doi.org/10.1590/S1415-52732003000400011

Instituto Brasileiro de Geografia e Estatística. (2010). Pesquisa de orçamento familiares 2008-2009: antropometria e estado nutricional de crianças, adultos e adolescentes. Rio de Janeiro: Autor.

Instituto Brasileiro de Geografia e Estatística. (2015). Síntese de indicadores sociais 2015 - Uma análise das condições de vida da população brasileira. Rio de Janeiro: Autor.

Jelinek, M., Romme, A. G. L., \& Boland, R. J. (2008). Introduction to the special issue: organization studies as a science for design: creating collaborative artifacts and research. Organization Studies, 29(3), 317-329. http://dx.doi.org./10.1177/0170840607088016 
Klein, V. H., Jr., Salm, J. F., Heidemann, F. G., \& Menegasso, M. E. (2012). Participação e coprodução em política habitacional: estudo de um programa de construção de moradias em SC. Revista de Administração Pública, 46(1), 25-48. http://dx.doi.org/10.1590/S0034-76122012000100003

Lei $n$. 8.080, de 19 de setembro de 1990. (1990). Dispõe sobre as condições para a promoção, proteção e recuperação da saúde, a organização e o funcionamento dos serviços correspondentes e dá outras providências. Recuperado de http://www.planalto.gov.br/ccivil_03/leis/18080.htm

Lucchese, G. (2001). Globalização e regulação sanitária: os rumos da vigilância sanitária no Brasil (Tese de doutorado). Escola Nacional de Saúde Pública, Fundação Oswaldo Cruz, Rio de Janeiro, RJ, Brasil.

Malta, D. C., Gosch, C. S., Buss, P., Rocha, D. G., Rezende, R., Freitas, P. C., \& Akerman, M. (2014). Doenças crônicas não transmissíveis e o suporte das ações intersetoriais no seu enfrentamento. Ciência \& Saúde Coletiva, 19(11), 4341-4350. http://dx.doi.org/10.1590/1413812320141911.07712014

Marchi, O. S. (2003). A municipalização das ações de vigilância sanitária no município de Florianópolis: diagnóstico estratégico situacional voltado para a identificação e desdobramento do problema e delimitação de estratégias de solução (Dissertação de mestrado). Universidade do Vale do Itajaí, Florianópolis, SC, Brasil.

Marston, C., Hinton, R., Kean, S., Baral, S., Ahuja, A., Costello, A., \& Portela, A. (2016). Community participation for transformative action on women's, children's and adolescents' health. Bull World Health Organ, 94(5), 376-382. http://dx.doi.org/10.2471/BLT.15.168492

Ministério da Saúde. (2002). As cartas da promoção da saúde (Série B. Textos Básicos em Saúde). Brasília, DF: Autor. Recuperado de http://bvsms.saude.gov.br/bvs/publicacoes/cartas_promocao.pdf

Ministério da Saúde. (2005). Guia alimentar para a população brasileira. Brasília, DF: Autor.

Ministério da Saúde. (2015). Vigitel Brasil 2014 - vigilância de fatores de risco e proteção para doenças crônicas por inquérito telefônico. Brasília, DF: Autor.

NYC Health. (n.d.). Restaurant grading in New York City at 18 months. Recuperado de https://www1.nyc.gov/assets/doh/downloads/pdf/rii/restaurant-grading-18-month-report.pdf

Osborne, S. P., Radnor, Z., \& Strokosch, K. (2016). Co-production and the co-creation of value in public services: a suitable case for treatment?. Public Management Review, 18(5), 639-653. http://dx.doi.org/10.1080/14719037.2015.1111927

Osborne, S. P., \& Strokosch, K. (2013). It takes two to tango? Understanding the co-production of public services by integrating the services management and public administration perspectives. British Journal of Management, 24(S1), S31-S47. http://dx.doi.org/10.1111/1467-8551.12010

Ostrom, E. (1996). Crossing the great divide: coproduction, synergy and development. World Development, 24(6), 1073-1087. http://dx.doi.org/10.1016/0305-750X(96)00023-X

Palumbo, R. (2016). Contextualizing co-production of health care: a systematic literature review. International Journal of Public Sector Management, 29(1), 72-90. http://dx.doi.org/10.1108/IJPSM-07-2015-0125

Pestoff, V. (2009). Towards a paradigm of democratic participation: citizen participation and coproduction of personal social services in Sweden. Annals of Public and Cooperative Economics, 80(2), 197-224. http://dx.doi.org/10.1111/j.1467-8292.2009.00384.x 
Poocharoen, O. O., \& Ting, B. (2015). Collaboration, co-production, networks: convergence of theories. Public Management Review, 17(4), 587-614. http://dx.doi.org/10.1080/14719037.2013.866479

Prefeitura de Florianópolis. (n.d.). Vigilância sanitária e ambiental. Recuperado em 28 agosto, 2015, de http://www.pmf.sc.gov.br/entidades/saude/index.php?cms=vigilancia+sanitaria+e+ambiental\& menu=9

Recine, E., \& Vasconcellos, A. B. (2011). Políticas nacionais e o campo da alimentação e nutrição em saúde coletiva: cenário atual. Ciência e Saúde Coletiva, 16(1), 73-79. http://dx.doi.org/10.1590/S1413-81232011000100011

Renedo, A., Marston, C. A., Spyridonidis, D., \& Barlow, J. (2015). Patient and public involvement in healthcare quality improvement: how organizations can help patients and professionals to $\begin{array}{lllll}\text { collaborate. Public } & \text { Management 17-34. }\end{array}$ http://dx.doi.org/10.1080/14719037.2014.881535

Roberts, N. (2004). Public deliberation in an age of direct citizen participation. The American Review of Public Administration, 34(4), 315-353. http://dx.doi.org/10.1177/0275074004269288

Salm, J. F., Schommer, P. C., Heidemann, F. G., Vendramini, P., \& Menegasso, M. E. (2011). Curso de administração pública da universidade do estado de Santa Catarina: uma construção à luz da coprodução do bem público e do novo serviço público [Edição Especial]. Temas de Administração Pública, 2(6), 1-30. http://seer.fclar.unesp.br/temasadm/article/view/6161/4630

Schmidt, M. I., Duncan, B. B., Silva, G. A., Menezes, A. M., Monteiro, C. A., Barreto, S. M., Chor, D., \& Menezes, P. R. (2011). Chronic non-communicable diseases in Brazil: burden and current challenges. The Lancet, 377(9781), 1949-1961. http://dx.doi.org/10.1016/S0140-6736(11)60135-9

Schommer, P. C, Andion, C. M., Pinheiro, D. M., Spaniol, E. L., \& Serafim, M. (2011). Coprodução e inovação social na esfera pública em debate no campo da gestão social. In P. C. Schommer \& R. F. Boullosa (Orgs.), Gestão social como caminho para a redefinição da esfera pública (pp. 3170). Florianópolis: Udesc Editora.

Secchi, L. (2013). Políticas públicas: conceitos, esquemas de análise, casos práticos (2a ed.). São Paulo: Cengage Learning.

Silveira, C. S. (1999). Vigilância em saúde meio ambiente e saúde pública: o caso do município de Florianópolis-SC (Dissertação de mestrado). Universidade Federal de Santa Catarina, Programa de Pós-Graduação em Engenharia Ambiental, Florianópolis, SC, Brasil.

Teixeira, C. F., \& Solla, J. P. (2006). Modelo de atenção à saúde: promoção, vigilância e saúde da família. Salvador, BA: EDUFBA. http://dx.doi.org/10.7476/9788523209209

Veiros, M. B., Proença, R. P. C., Kent-Smith, L., Hering, B., \& Souza, A. A. (2006). How to analyse and develop healthy menus in foodservice. Journal of Foodservice, 17(4), 159-165. http://dx.doi.org/10.1111/j.1745-4506.2006.00025.x

World Health Organization. (n.d.). Fact sheets: chronic diseases. Recuperado em 04 fevereiro, 2016, de http://www.who.int/topics/chronic_diseases/factsheets/en 


\section{Dados dos Autores}

Luiza Moritz Age

Avenida Madre Benvenuta, 2007, Itacorubi, 88035-001, Florianópolis, SC, Brasil. E-mail: luizamoritzage@ hotmail.com

Paula Chies Schommer

Avenida Madre Benvenuta, 2007, Itacorubi, 88035-001, Florianópolis, SC, Brasil. E-mail: paulacs3@ gmail.com 


\section{APÊNDICE}

\section{Roteiro de Inspeção para Certificação e Classificação de Restaurantes}

\begin{tabular}{|c|c|c|c|c|}
\hline \multirow[t]{2}{*}{ Item Área } & \multirow[t]{2}{*}{ Critério } & \multicolumn{3}{|c|}{ Pontuação } \\
\hline & & I.I & + & - \\
\hline $\begin{array}{l}\text { 1.1 Utensílios e Equipamentos Disponíveis } \\
\text { na Cozinha }\end{array}$ & Utiliza somente panelas de cerâmica ou inox & & 2 & \\
\hline $\begin{array}{l}\text { 1.2 Utensílios e Equipamentos Disponíveis } \\
\text { na Cozinha }\end{array}$ & Presença de forno combinado & & 6 & \\
\hline $\begin{array}{l}\text { 1.3 Utensílios e Equipamentos Disponíveis } \\
\text { na Cozinha }\end{array}$ & Ausência de fritadeira & & 8 & \\
\hline $\begin{array}{l}\text { 1.4 Utensílios e Equipamentos Disponíveis } \\
\text { na Cozinha }\end{array}$ & Presença de grelha & & 2 & \\
\hline 2.1 Matérias-primas utilizadas & $\begin{array}{l}\text { Tem horta própria para cultivo de temperos no } \\
\text { estabelecimento. }\end{array}$ & & 3 & \\
\hline 2.2 Matérias-primas utilizadas & $\begin{array}{l}\text { Faz controle da saturação do óleo de fritura } \\
\text { utilizando fita de monitoramento da saturação da } \\
\text { gordura ou tem controle da temperatura do óleo e } \\
\text { da saturação do óleo de fritura, substituindo-o de } \\
\text { acordo com o uso de forma padronizada, de } \\
\text { acordo com Procedimento Operacional Padrão. }\end{array}$ & & 4 & \\
\hline 2.3 Matérias-primas utilizadas & $\begin{array}{l}\text { Faz controle da saturação do óleo de fritura. } \\
\text { Substituindo-o de acordo com o uso de forma } \\
\text { padronizada. }\end{array}$ & $\mathrm{X}$ & & \\
\hline 2.4 Matérias-primas utilizadas & Utiliza somente ovos orgânicos ou caipiras. & & 4 & \\
\hline 2.5 Matérias-primas utilizadas & Utiliza algum tipo de corte de carne orgânica. & & 4 & \\
\hline 2.6 Matérias-primas utilizadas & $\begin{array}{l}\text { Não utiliza temperos prontos, molhos prontos, } \\
\text { amaciante de carnes e/ou outros produtos para } \\
\text { alterar consistência e/ou sabor dos alimentos } \\
\text { artificialmente, contendo: glutamato } \\
\text { monossódico e/ou gordura vegetal e/ou aditivos } \\
\text { artificiais. }\end{array}$ & $\mathrm{X}$ & & \\
\hline 2.7 Matérias-primas utilizadas & $\begin{array}{l}\text { Não utiliza carnes pré-temperadas } \\
\text { industrialmente. }\end{array}$ & $\mathrm{X}$ & & \\
\hline 2.8 Matérias-primas utilizadas & $\begin{array}{l}\text { Utiliza alimentos pré-prontos e prontos } \\
\text { industrializados. }\end{array}$ & & & 3 \\
\hline 2.9 Matérias-primas utilizadas & $\begin{array}{l}\text { Não utiliza gordura vegetal para preparo dos } \\
\text { alimentos. }\end{array}$ & $\mathrm{X}$ & & \\
\hline 3.1 Produtos Expostos ao Consumidor & $\begin{array}{l}\text { Disponibiliza pratos rasos de até } 22 \mathrm{~cm} \text { de } \\
\text { diâmetro ou } 70 \mathrm{~cm} \text { de circunferência. }\end{array}$ & & 4 & \\
\hline 3.2 Produtos Expostos ao Consumidor & $\begin{array}{l}\text { Oferece saladas na proporção de } 75 \% \text { ou mais da } \\
\text { quantidade total de acompanhamentos frios. }\end{array}$ & & 6 & \\
\hline 3.3 Produtos Expostos ao Consumidor & $\begin{array}{l}\text { Oferece saladas na proporção de } 50 \% \text { ou mais da } \\
\text { quantidade total de acompanhamentos frios. }\end{array}$ & $\mathrm{X}$ & & \\
\hline 3.4 Produtos Expostos ao Consumidor & Utiliza verduras, hortaliças ou frutas orgânicas. & & 6 & \\
\hline
\end{tabular}




\begin{tabular}{|c|c|c|c|c|}
\hline 3.5 Produtos Expostos ao Consumidor & $\begin{array}{l}\text { Oferece sementes e grãos para acompanhar a } \\
\text { salada. }\end{array}$ & & 3 & \\
\hline 3.6 Produtos Expostos ao Consumidor & $\begin{array}{l}\text { Oferece azeite de oliva extravirgem, mantido na } \\
\text { embalagem original, para acompanhar a salada. }\end{array}$ & & 2 & \\
\hline 3.7 Produtos Expostos ao Consumidor & $\begin{array}{l}\text { Disponibiliza molhos industrializados para } \\
\text { acompanhar a salada. }\end{array}$ & & & 6 \\
\hline 3.8 Produtos Expostos ao Consumidor & Oferece arroz integral. & & 1 & \\
\hline 3.9 Produtos Expostos ao Consumidor & $\begin{array}{l}\text { Oferece opções de preparações de alimentos não } \\
\text { refinados com grande teor de carboidrato, não } \\
\text { fritos, sem molhos gordurosos ou açucarados } \\
\text { (como batatas, aipim, outros tipos de arroz). }\end{array}$ & & 2 & \\
\hline 3.10 Produtos Expostos ao Consumidor & $\begin{array}{l}\text { Oferece preparações a base de carboidratos } \\
\text { contendo farinhas integrais (como pastel de } \\
\text { forno, quiche, pães). }\end{array}$ & & 1 & \\
\hline 3.11 Produtos Expostos ao Consumidor & $\begin{array}{l}\text { Oferece opção de preparação de leguminosa, sem } \\
\text { presença de carnes ou embutidos. }\end{array}$ & $\mathrm{X}$ & & \\
\hline 3.12 Produtos Expostos ao Consumidor & $\begin{array}{l}\text { Oferece preparações à base de carnes magras, na } \\
\text { proporção de } 50 \% \text { ou mais da quantidade total de } \\
\text { preparações à base de carne (item não aplicável } \\
\text { aos restaurantes vegetarianos/veganos). }\end{array}$ & $\mathrm{X}$ & & \\
\hline 3.13 Produtos Expostos ao Consumidor & $\begin{array}{l}\text { Oferece preparações proteicas vegetarianas } \\
\text { alternativas a carnes preparadas de forma não } \\
\text { frita, à base de grão de bico, lentilha, quinoa, } \\
\text { cogumelos, tofu, ovos. }\end{array}$ & & 7 & \\
\hline 3.14 Produtos Expostos ao Consumidor & Não oferece preparações fritas. & & 8 & \\
\hline 3.15 Produtos Expostos ao Consumidor & $\begin{array}{l}\text { Oferece preparações fritas na proporção de } 20 \% \\
\text { ou menos da quantidade total de preparações } \\
\text { quentes. }\end{array}$ & $\mathrm{X}$ & & \\
\hline 3.16 Produtos Expostos ao Consumidor & $\begin{array}{l}\text { Não oferece preparações contendo } \\
\text { predominantemente alimentos embutidos } \\
\text { e/conservas ou recheados com estes (como } \\
\text { acompanhamentos frios, torta fria, pastéis, } \\
\text { quiches, lasanhas e outros). }\end{array}$ & & 8 & \\
\hline 3.17 Produtos Expostos ao Consumidor & $\begin{array}{l}\text { Oferece preparações contendo } \\
\text { predominantemente alimentos embutidos e/ou } \\
\text { conservas na proporção de } 10 \% \text { ou menos da } \\
\text { quantidade total de preparações quentes. }\end{array}$ & $\mathrm{X}$ & & \\
\hline 3.18 Produtos Expostos ao Consumidor & $\begin{array}{l}\text { Não oferece sobremesa ou oferece opção de fruta } \\
\text { in natura entre as sobremesas. }\end{array}$ & & 4 & \\
\hline 3.19 Produtos Expostos ao Consumidor & Incentiva o consumo de sobremesas doces. & & & 6 \\
\hline 3.20 Produtos Expostos ao Consumidor & Oferece suco natural sem adição de açúcar. & $X$ & & \\
\hline 3.21 Produtos Expostos ao Consumidor & $\begin{array}{l}\text { Incentiva o consumo de suco natural em } \\
\text { detrimento a outras bebidas. }\end{array}$ & & 2 & \\
\hline 3.22 Produtos Expostos ao Consumidor & Disponibiliza sal para os clientes. & & & 5 \\
\hline 4.1 Ambiente & $\begin{array}{l}\text { Expõe, em local visível ao consumidor, Alvará } \\
\text { Sanitário válido. }\end{array}$ & $\mathrm{X}$ & & \\
\hline 4.2 Ambiente & $\begin{array}{l}\text { Disponibiliza os ingredientes de cada preparação, } \\
\text { em plaquinhas próximas, no bufê. }\end{array}$ & $\mathrm{X}$ & & \\
\hline
\end{tabular}




\begin{tabular}{llll}
\hline 4.3 Ambiente & $\begin{array}{l}\text { Disponibiliza informações que incentivam o } \\
\text { consumo de sucos naturais. }\end{array}$ & 1 \\
\hline 4.4 Ambiente & $\begin{array}{l}\text { Disponibiliza informações que incentivam o } \\
\text { consumo de saladas. }\end{array}$ & 4 \\
\hline 4.5 Ambiente & $\begin{array}{l}\text { Não expor propagandas de refrigerantes, sucos } \\
\text { artificiais e/ou chás artificiais. }\end{array}$ & $\mathrm{X}$ \\
\hline 5.1 Documentos & $\begin{array}{l}\text { Apresenta Manual de Boas Práticas que inclui } \\
\text { Procedimentos Operacionais Padrão de controle } \\
\text { do sódio nas preparações servidas. }\end{array}$ & 8 \\
\hline 5.2 Documentos & $\begin{array}{l}\text { Apresenta profissional nutricionista como } \\
\text { responsável técnico pelo estabelecimento, } \\
\text { certificado pelo Conselho Regional de } \\
\text { Nutricionistas. }\end{array}$ & $\begin{array}{l}\text { Apresenta profissional nutricionista como } \\
\text { consultor/assessor do estabelecimento, } \\
\text { comprovado por contrato de trabalho. }\end{array}$ \\
\hline 5.3 Documentos & & 4 \\
\hline
\end{tabular}

TOTAL

Nota. *Os itens 5.2 e 5.3 são excludentes, portanto a maior pontuação possível a ser obtida são 100 pontos.

\section{Classificações}

Restaurante Certificado - aquele que cumpre todos os itens de cumprimento indispensável.

Classificação em três estrelas - obtida pelo restaurante que cumprir todos os itens indispensáveis e obtiver soma de até 20 pontos entre os itens com pontuação atribuída.

Classificação em quatro estrelas - obtida pelo restaurante que cumprir todos os itens indispensáveis e obtiver soma de 21 a 50 pontos entre os itens com pontuação atribuída.

Classificação em cinco estrelas - obtida pela restaurante que cumprir todos os itens indispensáveis e obtiver soma acima de 51 pontos entre os itens com pontuação atribuída.

\section{Observações}

I.I. - Item de cumprimento indispensável para a Certificação.

+ - Pontuação positiva atribuída ao item.

- - Pontuação negativa atribuída ao item.

\section{Definições}

Acompanhamentos frios: preparações expostas no bufê frio, exceto saladas.

Alimentos orgânicos: serão considerados orgânicos quando apresentada cópia do certificado de orgânico do alimento, combinado com nota fiscal de compra ou quando verificado selo de orgânico na embalagem do produto.

Alimentos pré-prontos ou prontos industrializados: aqueles que são comprados prontos ou pré-prontos de fornecedores terceirizados (molhos, massas prontas, carnes temperadas, batatas pré-fritas e outros). 
Preparações à base de carnes magras: em modo de preparo assado, cozido ou grelhado, sem adição de molhos gordurosos, sem pele, sem gordura aparente, nos cortes bovinos de patinho, picanha, coxão duro, músculo, lagarto, filé mignon, alcatra; suínos de lombo; frango; peixes e frutos do mar.

Ficha Técnica de Preparação: receita padronizada do restaurante que apresenta todos os ingredientes da preparação, as técnicas de preparo e o rendimento.

Forno combinado: equipamento que funciona combinando ar quente e vapor, controlados por sensor, para cocção dos alimentos.

Incentivo ao consumo: realizado através da redução de preço, oferecimento de gratuidades ou disponibilidade de informações sobre determinado alimento ou bebida.

Molho industrializado/molho pronto: aquele adquirido pronto ou preparado no local, derivado da mistura de molhos adquiridos prontos.

Molhos gordurosos: aqueles contendo leite integral e/ou queijos e/ou creme de leite e/ou nata e/ou grande quantidade de óleo (ingredientes serão verificados pela fica técnica de preparo).

Preparações à base de carboidratos contendo farinhas integrais: a presença de farinha integral será verificada pela ficha técnica de preparação do alimento, quando produzido no local, que deverá ser maior que $30 \%$ do total da quantidade de farinhas e; pela embalagem do alimento, quando industrializado, que deverá conter farinha integral como primeiro ingrediente.

Preparações à base de carnes: preparações que tem como ingrediente único ou principal carne bovina, de frango, suína, frutos do mar e outras carnes (bife ao molho, frango ensopado, peixe assado, estrogonofe de camarão e outras).

Preparações fritas: aquelas que têm como modo de cocção a imersão em óleo/gordura.

Preparações proteicas vegetarianas alternativas a carnes: preparações que não contém carnes e que contém fontes de proteína vegetal, que possam substituir as carnes como prato principal da refeição.

Preparações quentes: preparações expostas no buffet quente, incluindo aquelas à base de carnes (arroz, macarrão, lasanha, batata frita, carnes).

Salada: preparação fria contendo como único ou principal ingrediente verduras e/ou hortaliças e/ou frutas cruas ou cozidas, podendo ser utilizados na preparação outros ingredientes tais como embutidos e conservas apenas como enfeites.

Sobremesas doces: preparações oferecidas no bufê de sobremesas que não são frutas in natura.

Suco natural: suco feito somente da fruta, no estabelecimento; suco feito de polpa congelada da fruta, no estabelecimento; suco industrializado sem adição de conservantes e outros ingredientes além da fruta. 